\title{
Fiebre persistente en paciente inmunodeprimido
}

\author{
Persistent fever in a immunocompromised patient
}

\author{
Díaz-Gutiérrez $\mathrm{MM}^{1}$, Albors-Ferreiro $\mathrm{M}^{2}$, Penin-Corderi MC ${ }^{3}$ \\ ${ }^{1}$ Servicio de Neumoloxía; Complexo Hospitalario Universitario de Ourense. \\ ${ }^{2}$ Servicio de Hematoloxía e Hemoterapia; Complexo Hospitalario Universitario de Ourense. \\ ${ }^{3}$ Jefa de Servicio. Servicio de Anatomía Patolóxica; Complexo Hospitalario Universitario de Ourense.
}

\section{Resumen}

La enfermedad tuberculosa del sistema nervioso central (SNC) es una patología infrecuente pero que conlleva elevada morbi-mortalidad. Se presenta con mayor frecuencia en ciertos grupos de riesgo, como la inmunodepresión. Para intentar mejorar el pronóstico de estos pacientes resulta fundamental la sospecha diagnóstica para iniciar tratamiento etiológico de forma precoz.

Palabras clave: absceso, tuberculosis, sistema nervioso central, paciente inmunodeprimido.

Se presenta el caso de un paciente con pancitopenia febril en el contexto de una leucemia linfática crónica, a tratamiento quimioterápico en el momento del ingreso. Entre los antecedentes personales destacan diabetes mellitus, hepatopatía crónica de origen enólico y por virus B, con serología VIH negativa y episodios de insuficiencia cardíaca congestiva que requirieron múltiples ingresos hospitalarios. En un ingreso previo al actual presentó bacteriemia por Corynebacterium $s p$. orientado como posible contaminante de la muestra.

El paciente fue diagnosticado en 2005 de leucemia linfática crónica B estadio A/0, con seguimiento errático. Se objetiva evolución a estadio C/IV, y en junio de 2014 se inicia tratamiento inmunoquimioterápico con esquema R-FC (rituximab 375 $\mathrm{mg} / \mathrm{m} 2$ iv (intravenoso), fludarabina $25 \mathrm{mg} / \mathrm{m} 2$ iv, ciclofosfamida $250 \mathrm{mg} / \mathrm{m} 2 \mathrm{iv})$. Tras recibir el segundo ciclo de R-FC se objetiva neutropenia grado 3 de la OMS crónica que se pone en relación con fludarabina, por lo que se decide continuar con un esquema de menor toxicidad: R-CVP (rituximab $375 \mathrm{mg} / \mathrm{m} 2$ iv, ciclofosfamida $750 \mathrm{mg} / \mathrm{m} 2 \mathrm{iv}$, vincristina $2 \mathrm{mg}$ iv, prednisona $100 \mathrm{mg}$ vía oral (vo) durante 4 días) iniciado el 16.09.14.

El paciente ingresa el 16.11.2014 a causa de un cuadro de deshidratación moderada e insuficiencia renal en el contexto de un síndrome diarreico y emético persistente. A su llegada se objetiva una temperatura de $37.2^{\circ} \mathrm{C}$, con diarrea sin productos patológicos. № se evidencian adenopatías a nivel cervical, axilar ni inguinal.

Los principales resultados analíticos se recogen en la tabla 1:

Tabla 1. Principales resultados analíticos al ingreso

\begin{tabular}{|c|c|}
\hline Hemoglobina & $7,8 \mathrm{mg} / \mathrm{dL}$ \\
\hline Plaquetas & $34000 / \mu \mathrm{L}$ \\
\hline Neutrófilos & $420 / \mu \mathrm{L}$ \\
\hline Linfocitos & $70 / \mu \mathrm{L}$ \\
\hline Creatinina & $3,2 \mathrm{mg} / \mathrm{dL}$ \\
\hline Filtrado glomerular & $19 \mathrm{~mL} / \mathrm{min}$ \\
\hline Urea & $254 \mathrm{mg} / \mathrm{dL}$ \\
\hline
\end{tabular}

Correspondencia: manuel.albors.ferreiro@sergas.es

Como citar este artículo: Díaz-Gutiérrez MM, Albors-Ferreiro M, Penin-Corderi MC

\section{Abstract}

Central nervous system tuberculosis is a rare disease but carries high morbidity and mortality. It occurs most frequently in certain risk groups, such as immunosuppression. To try to improve the prognosis of these patients suspected diagnosis is essential to start treatment early etiologic.

Keywords: Abscess, Tuberculosis, immunocompromised patient, central nervous system.

Se inicia antibioterapia empírica con piperacilina-tazobactam con dosis ajustada a su función renal. A pesar del tratamiento persisten picos febriles de hasta $40^{\circ} \mathrm{C}$ y ante la ausencia de aislamientos microbiológicos (hemocultivos, urocultivos, y cultivo de esputo negativos), se añade teicoplanina 400mg/24h iv (las tres primeras dosis administradas cada 12h). Al tercer día de ingreso, el cuadro abdominal se resuelve por completo, con persistencia de la fiebre. Ante la carencia de aislamiento microbiológico y tratándose de un paciente inmunodeprimido se decide compaginar tratamiento con meropenem $1 \mathrm{~g} / 8 \mathrm{~h}$ iv, caspofungina $70 \mathrm{mg}$ iv de carga y a continuación 50mg/24h iv, trimetoprim-sulfametoxazol 160/800mg diario iv y teicoplanina a la dosis descrita previamente, teniendo en cuenta la historia previa de aislamiento de Corynebacterium sp.

Tras una semana de ingreso, el paciente desarrolla anisocoria reactiva acompañada de bradipsiquia no presente en exámenes previos. El resto de pares craneales no sufren alteraciones, ni tampoco existen signos meníngeos. A la vista de esta clínica neurológica junto con el antecedente neoplásico, la trombopenia crónica y los importantes factores de inmunosupresión (diabetes mellitus, enolismo crónico, inmunodepresión celular por fludarabina) se solicita tomografía computerizada (TC) craneal y punción lumbar para evaluar la sospecha clínica de infiltración neoplásica, hemorragia o infección. Al noveno día de ingreso, sufre un nuevo empeoramiento clínico, esta vez incluyendo disminución del nivel de conciencia.

En el estudio de imagen (TC y resonancia magnética) se objetivan 8-10 lesiones supra e infratentoriales la de mayor tamaño en la región paramedial parietal derecha y acompañada de edema perilesional. Tras la administración de contraste se observa realce periférico pseudonodular, con áreas hipointensas en T2 sin datos de sangrado (Fig1).

Estos hallazgos obligan a plantear diagnóstico diferencial entre abscesos cerebrales y posible afectación metastásica de su proceso hematológico basal. En el supuesto 
infeccioso, planteamos como los agentes etiológicos más frecuentes bacterias aerobias (Streptococcus grupo viridans, Staphylococcus, Listeria monocitogenes, Nocardia $s p$ ), anaerobias, hongos (Aspergillus sp) o parásitos (Toxoplasma). Se ajusta de nuevo el tratamiento con meropenem, ampicilina 1g/4h iv, linezolid 600mg/12h 2 días iv y posteriormente vo, caspofungina y trimetoprim-sulfametoxazol 800/160/24h vía oral tres veces por semana de forma profiláctica. Se añade levetiracetam $500 \mathrm{mg} / 12 \mathrm{~h}$ vía oral como profilaxis de crisis comiciales y filgastrim por la neutropenia (30 MU/0,5 mL subcutáneo c/24h).

En este momento permanece afebril por primera vez desde su llegada, con mejoría leve de la bradipsiquia. Se descarta endocarditis mediante ecocardiograma transesofágico, y en cuanto a la serología resulta negativa para Aspergillus y Toxoplasma. El resultado de la punción lumbar fue normal: 3 leucocitos/ $\mu \mathrm{L}$, glucosa $47 \mathrm{mg} / \mathrm{dL}$, proteínas $20 \mathrm{mg} / \mathrm{dL}$, con niveles de adenosina deaminasa (ADA) de $4 \mathrm{U} / \mathrm{L}$.

En este momento inicia síntomas respiratorios con roncus a la auscultación, por lo que se solicita radiografía de tórax, que muestra un patrón intersticial (Fig2). Ante este hallazgo se solicita una tomografía computarizada de tórax-abdomen-pelvis para evaluar el patrón intersticial pulmonar y la presencia de abscesos a otros niveles.

La prueba demuestra severa afectación parenquimatosa pulmonar difusa y bilateral, que muestra patrón micronodular con algunos infiltrados acinares, así como amplias áreas de infiltración a modo de vidrio deslustrado que sugieren infección por citomegalovirus o bien tuberculosis miliar (Fig3). Ante la falta de aislamientos microbiológicos se valora con el servicio de Neurocirugía la posibilidad de obtener una muestra mediante biopsia de las lesiones cerebrales para conseguir filiar su etiología. La masa más accesible y de mayor tamaño, localizada a nivel parietal derecho, presenta un elevado riesgo de hemiparesia residual, por lo que se consensua tratamiento conservador.

La decisión de no intervención se ve favorecida así mismo por la obtención de una muestra de esputo con tinción de auramina positiva con PCR positiva para Mycobacterium tuberculosis, por lo que se procede a aislar al enfermo y modificar el tratamiento antibiótico, indicando la combinación de etambutol $1100 \mathrm{mg} / 24 \mathrm{~h}$, isoniacida 300 mg/24h, piranizamida $1600 \mathrm{mg} / 24 \mathrm{~h}$ y rifampicina $600 \mathrm{mg} / 24 \mathrm{~h}$ bajo la sospecha de tuberculosis activa, y se mantienen trimetoprim-sulfametoxazol 800/160 mg cada 24h iv y linezolid $600 \mathrm{mg} / 12 \mathrm{~h}$ vo.

La evolución es desfavorable con deterioro del estado general, sin focalidad motora neurológica y desarrollando estupor y posteriormente coma. Finalmente es éxitus a los 3 meses de inicio del cuadro.

Se realizó necropsia que evidenció abundante presencia de bacilos con tinción Zhiel-Neelsen positiva en las lesiones cerebrales (Fig4,5), compatible con M. tuberculosis.
Figura 1. Resonancia magnética mostrando múltiples masas cerebrales. En este corte se muestra la lesión de mayor tamaño a nivel paramedial parietal derecha con importante edema perilesional, presentando áreas hipointensas en T2 con ausencia de datos de sangrado.

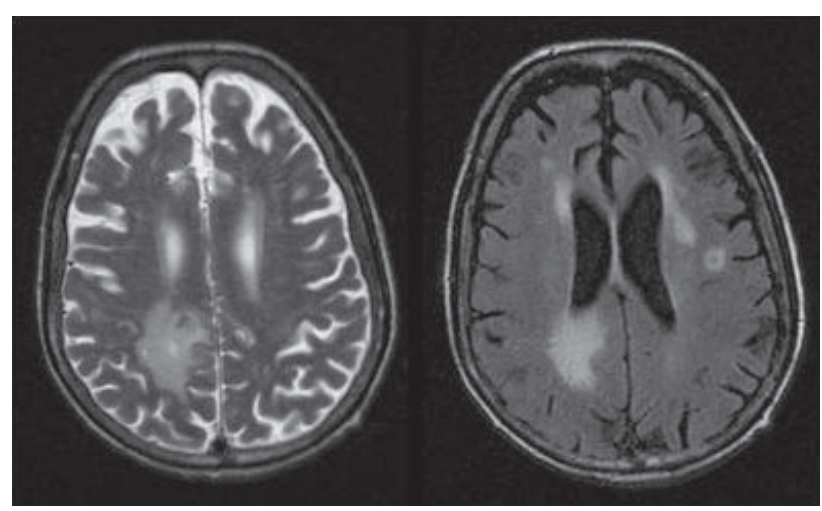

Figura 2. Radiografía de tórax en proyección AP. Aumento de densidad en ambos campos pulmonares con patrón retículo nodulillar, acompañado de engrosamiento hiliar bilateral.

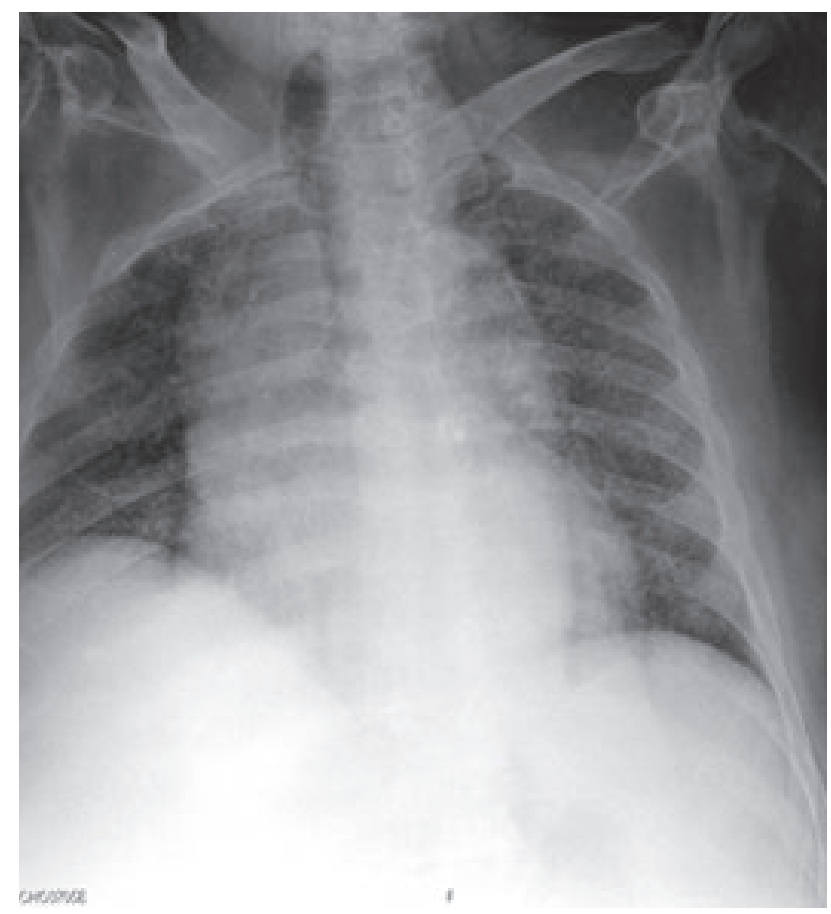

Figura 3. Tomografía computarizada de tórax, donde se observa una extensa afectación difusa y bilateral del parénquima pulmonar con patrón reticulonodular.

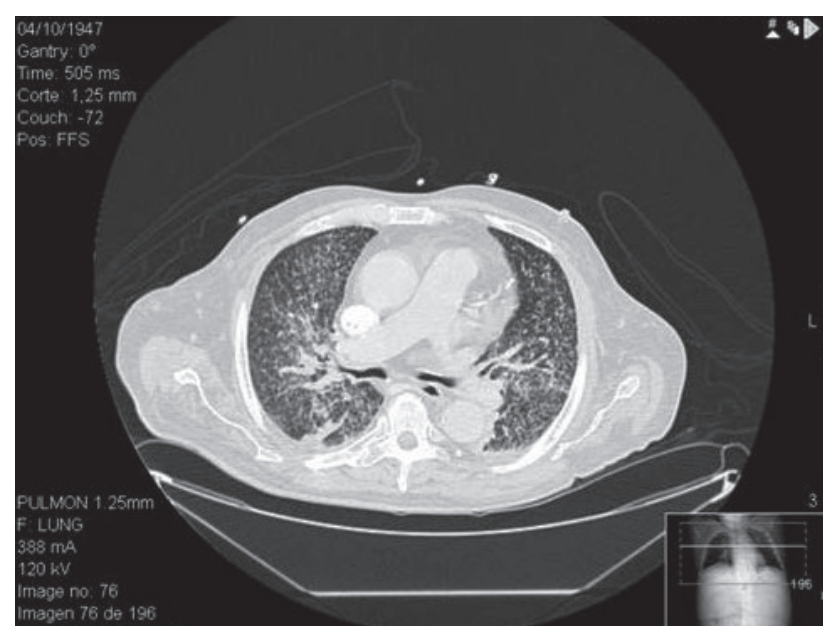


Figura 4. Tinción Zhiel-Neelsen, 4x. Muestra de biopsia cerebral obtenida en estudio de necropsia, mostrando múltiples bacilos ácido- alcohol resistentes en tejido del sistema nervioso central.

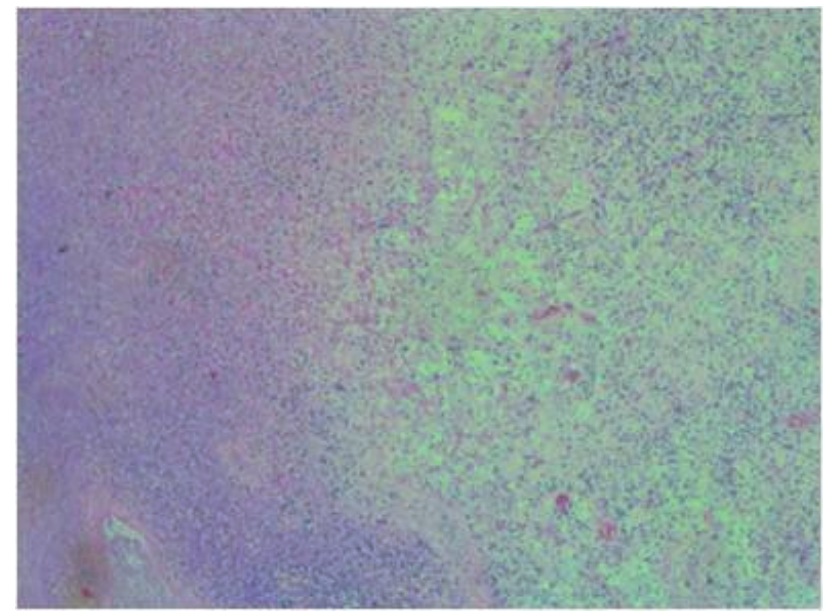

\section{Discusión y conclusiones}

La afectación tuberculosa de sistema nervioso central (SNC) no es frecuente, ocurriendo según la descripción de series previas publicadas entre un $10-15 \%$ de los casos de tuberculosis. Entre las formas de afectación, la meningitis tuberculosa es la diagnosticada con mayor frecuencia. Otras formas de presentación menos habitual son los tuberculomas y los abscesos tuberculosos $[1,2]$.

Los tuberculomas suponen el $4 \%$ de las masas intracraneales en países de nuestro entorno, ascendiendo hasta el 15-30\% en países en desarrollo. En dos tercios de los casos son de presentación única y es frecuente que no se acompañen de manifestaciones clínicas de la infección tuberculosa primaria [2].

Los abscesos cerebrales tuberculosos son manifestación rara de tuberculosis. Pueden generarse desde tuberculomas parenquimatosos o por diseminación de micobacterias desde focos meníngeos. Se caracteriza por una colección en- capsulada de pus que contiene bacilos viables sin evidencia del granuloma tuberculoso clásico y debe distinguirse del granuloma con caseificación central y licuefacción imitando pus. Pueden surgir como lesiones únicas o múltiples [1].

A pesar de ser una patología poco habitual, origina una importante repercusión en términos de morbi-mortalidad, por lo que para obtener un resultado favorable resulta fundamental la sospecha diagnóstica y el tratamiento precoz, sobre todo si existe predisposición [3]. En una serie de 116 casos en los que se obtuvo confirmación microbiológica 0 histológica de micobacterias, la evolución fue satisfactoria en el 83\% de los mismos [4].

Se han identificado diversos factores de riesgo para el desarrollo de afectación tuberculosa del SNC. Entre ellos destacan la edad pediátrica y la infección por VIH. Otros de estos factores son la malnutrición, el alcoholismo, neoplasias y el tratamiento inmunosupresor [1].

La tríada clínica típica incluye fiebre, cefalea y alteración del estado mental. La presentación de los tres síntomas al mismo tiempo fue poco frecuente en las series revisadas. Estas manifestaciones pueden ser acompañadas por otras específicas en función de la localización de las lesiones, como convulsiones 0 signos de hipertensión intracraneal como papiledema [1,5-8].

El diagnóstico de los abscesos tuberculosos intracraneales supone un reto. Su comportamiento clínico puede imitar diversas patologías y por sus manifestaciones radiológicas, plantean diagnóstico diferencial con otras lesiones que presentan realce en anillo en la TC con contraste, como neoplasias y abscesos bacterianos o fúngicos [2,9].

El análisis del líquido cefalorraquídeo habitualmente refleja alteraciones. Es frecuente la presencia de pleocitosis linfocitaria y proteinorraquia. $[1,4]$. Se ha demostrado determinación de ADA es útil en el diagnóstico de la meningitis tuberculosa, aunque como en nuestro caso, puede ser normal si la diseminación no se produce desde un foco meníngeo [1]. La biopsia estereotáctica puede ser diagnóstica, pero sólo

Figura 5. Tinción Zhiel-Neelsen 40x y ampliación. Se observan abundantes bacilos ácido-alcohol resistentes en el tejido cerebral en ausencia de formación de los característicos granulomas tuberculosos.

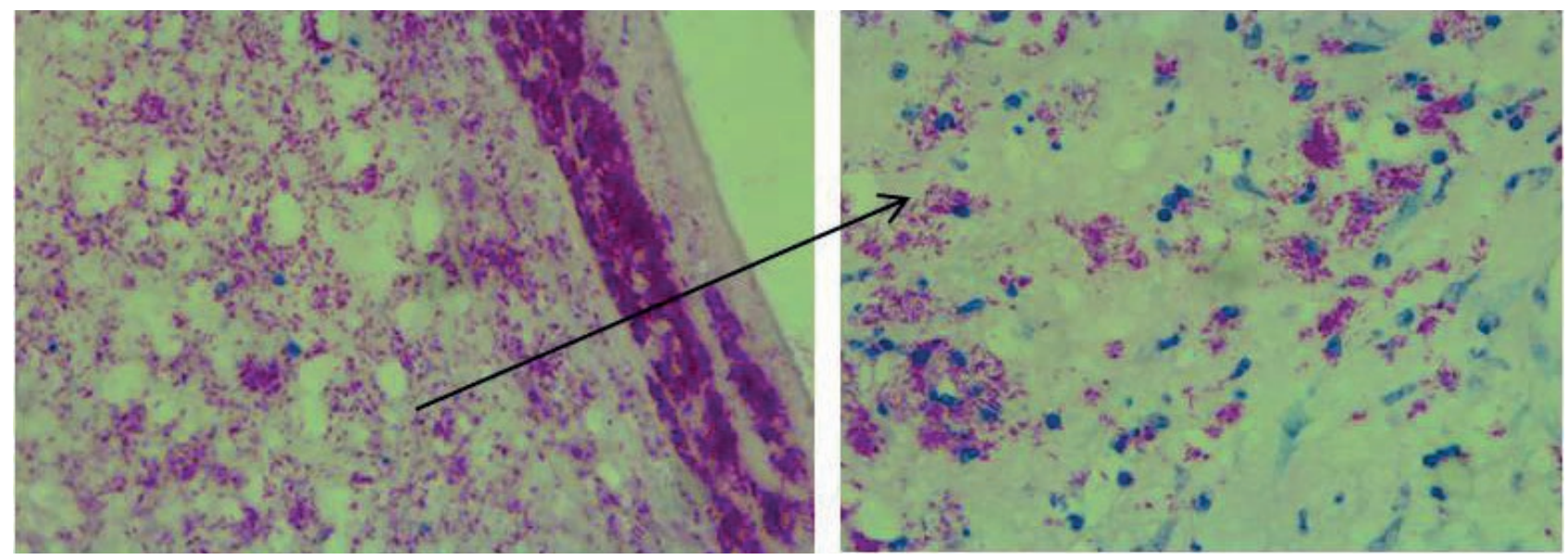


se recomienda cuando no se puede alcanzar el diagnóstico por otros medios menos invasivos [10].

El tratamiento médico inicial se basa en la combinación de rifampicina, isoniacida, pirazinamida y etambutol o estreptomicina. Otros agentes como fluorquinolonas, capreomicina, linezolid se pueden usar como segunda línea. [10] Así mismo, al margen del tratamiento etiológico, el uso de corticoides está ampliamente aceptado como terapia coadyuvante. [1,6-8] El tratamiento neuroquirúrgico se recomienda en casos de hipertensión intracraneal o compresión del SNC. [10] En el caso de nuestro paciente, éste presentaba múltiples factores de riesgo para el desarrollo de abscesos cerebrales tuberculosos. Tenía antecedentes de alcoholismo, padecía una neoplasia y había sido expuesto a tratamiento quimioterápico. A pesar de no ser seropositivo para VIH, presentaba una inmunodepresión celular intensa debido a la linfopenia secundaria a fludarabina. Dada su pluripatología, debíamos plantearnos el diagnóstico diferencial de las lesiones incluyendo infecciones bacterianas y micóticas habituales, así como patógenos menos habituales pero asociados con inmunodepresión como Listeria, Nocardia, Toxoplasma, Aspergillus, tuberculosis o incluso procesos metastásicos en relación a la enfermedad hematológica. Ante la ausencia de foco infeccioso claro, sin cultivos positivos y la persistencia de elevada temperatura se decidió cobertura antibiótica amplia, pero a pesar de ella la demora diagnóstica produjo un retraso en el correcto tratamiento, que probablemente influyó al mal pronóstico.

Como conclusión, cabría decir que constituye una patología con una elevada morbi-mortalidad, a lo que se suma un difícil diagnóstico y retraso en el tratamiento adecuado, hecho que empeora en pacientes con inmunodepresión. En las últimas décadas han mejorado las cifras de supervivencia, fundamentalmente gracias a las técnicas de imagen, la biopsia estereotáctica y a los regímenes antibióticos $[7,8]$, pero a pesar de ello presenta una morbilidad nada despreciable, fundamentalmente a costa de secuelas neurológicas. Por todo ello resulta de gran importancia la sospecha clínica temprana e instauración de tratamiento antibiótico adecuadamente dirigido al germen causal.

\section{Bibliografía}

1. Rock RB, Olin M, Baker CA, Molitor TW, Peterson PK. Central Nervous System Tuberculosis: Pathogenesis and Clinical Aspects. Clinical Microbiology Reviews. 2008; 21(2):243-61.

2. Salaskar AL, Hassaneen W, Keenan $\mathrm{CH}$, Suki D. Intracranial tuberculoma mimicking brain metastasis. J Cancer Res Ther. 2015 Jul-Sep; 11(3):653.

3. Sütla区 PN, Unal A, Forta $H$, Senol $S$, Kirba区 D. Tuberculous meningitis in adults: review of 61 cases. Infection. 2003 Dec; 31(6):387-91.

4. Psimaras D, Bonnet C, Heinzmann A, Cárdenas G, Hernández JLS, Tungaria A et al. Solitary tuberculous brain lesions: 24 new cases and a review of the literature. Rev Neurol (Paris). 2014 Jun-Jul; 170(6-7):454-63.

5. Gutiérrez-Cuadra M, Ballesteros MÁ, Vallejo A, Miñambres E, Fariñas-Álvarez C, García-Palomo JD et al. Abscesos cerebrales en un hospital de tercer nivel: epidemiología y factores que influyen en la mortalidad. Rev Esp Quimioter. 2009; 22(4):201206

6. A. Nelson C., R. Zunt J. Tuberculosis of the Central Nervous System in Immunocompromised Patients: HIV Infection and Solid Organ Transplant Recipients. Clin Infect Dis. 2011; 53(9):915-26.

7. Brouwer MC, Tunkel AR, McKhann II GM, van de Beek D. Brain Abscess. N Engl J Med. $2014 ; 371(5): 447-56$

8. Brouwer MC, Coutinho JM, van de Beek D. Clinical characteristics and outcome of brain abscess. Neurology 2014; 82:806-13.

9. Tanizaki R, Takasaki J. Tuberculoma. Intern Med. 2014; 53(13):1457-58

10. DeLance AR, Safaee M, Oh MC, Clark AJ, Kaur G, Sun MZ et al. Tuberculoma of the central nervous system. J Clin Neurosci. 2013 Oct; 20(10):1333-41

\section{Normas de publicación Galicia Clínica}

Galicia Clínica es la revista oficial de la Sociedad Gallega de Medicina Interna (SOGAMI). Se publican 4 números al año, simultáneamente en papel y en www.galiciaclinica.info, incluyéndose en el segundo de ellos las comunicaciones enviadas a la correspondiente Reunión Ordinaria de la SOGAMI.

GALICIA CLÍNICA evaluará para su publicación trabajos médicos relacionados preferentemente con la Medicina Interna y sus subespecialidades, y/o con problemas médicos prevalentes en la Comunidad Autónoma de Galicia. Se admitirán para evaluación trabajos en castellano, gallego, inglés y portugués.

Para el envío de originales se ha habilitado un formulario en la pagina web uww.galiciaclinica.info. El sistema confirmará la entrega y permitirá consultar el estado del manuscrito. No se aceetarán originales enviados por otros métodos.

El comité editorial, eventualmente con la ayuda de revisores externos, evaluará los trabajos enviados decidiendo si procede su publicación, si es necesario realizar correcciones o si se desestima la publicación. Una vez aceptado, se procede su publicación, si es necesario realizar correcciones o si se desestima la

Los trabajos reunirán los requisitos de uniformidad habituales en revistas biomédicas. Dichos requisitos se pueden consultar en "Uniform Requirements for Manuscripts Submitted to Biomedical Journals: Writing and Editing for Biomedical Publication, Updated April 2010", disponible en http://wwwwicmje.org. Se recomienda encarecidamente leer en especial la sección "Preparing a Manuscript for Submission to a Biomedical Journal" (http://uww.icmje.org/ manuscript_1 prepare.html) y seguir fielmente sus indicaciones a la hora de redactar el trabajo a enviar.

Se recomienda el empleo de los programas más habituales de edición de texto (Ej., Word) tanto para el texto como para las tablas.

Dado que la mayoría de las páginas se imprimen en blanco y negro, se aconseja evitar en tablas y figuras en la medida de lo posible el uso de colores o tramas que no tengan el adecuado contraste para su identificación. Las figuras o imágenes se enviarán en archivo aparte, como archivo de imagen (jpeg o similar) o como PDF con una resolución de 300 ppp. a tamaño de impresión definitivo.

La revista presenta las siguientes secciones:

Editoriales

Habitualmente encargados por la dirección de la revista. Su extensión máxima será de 8 páginas de 30 líneas y se admitirá una figura 0 una tabla y quince citas bibliográficas.

El número máximo de firmantes será de dos.

Originales

Trabajos de investigación sobre cualquier aspecto médico. La estructura general de los trabajos será la tradicional: Título: en el idioma original y en inglés, Resumen y Abstract en inglés, Palabras clave y Key words (que deben corresponder a los medical subjets headings -MESH- del Index Medicus), Introducción, Material y métodos, Recorresponder a los medical subjos, Discusión, Bibliografía

La extensión máxima recomendada del texto es de 20 páginas de 30 líneas, a las que se podrán añadir 5 figuras y 5 tablas, y un máximo de 30 citas bibliográficas.

El número máximo de firmantes será de ocho.

Originales breves

Trabajos de investigación que por sus características no precisan un mayor espacio. Estructura similar a la de los originales. Su extensión máxima será de 10 páginas de 30 lineas, 3 figuras, 3 tablas y 20 citas bibliográficas.

El número máximo de firmantes será de seis.
Revisiones

Habitualmente encargadas por la dirección de la revista. La extensión máxima recomendada del texto es de 30 páginas de 30 líneas, a las que se podrán añadir 6 figuras y 6 tablas, y un máximo de 50 citas bibliográticas. El número máximo de firmantes será de tres.

Preguntas clínicas

En esta sección se tratará de responder de forma concreta y sucinta a preguntas clínicas concretas que, bien han motivado una controversia, o cuestionan actitudes arraigadas en la práctica diaria. La extensión máxima será de 6 páginas de 30 líneas, dos figuras y dos tablas y 15 citas bibliográficas.

El número máximo de firmantes será de dos.

Notas clínicas

Descripción de casos clínicos de excepcional interés. Constarán de una breve introducción, caso clínico, y discusión correspondiente. Su extensión máxima será de 6 páginas, 2 figuras y dos tablas y 15 citas bibliográficas.

El número máximo de firmantes será de cuatro.

Cartas al director

Comentarios, opiniones u observaciones sobre los diversos trabajos publicados con anterioridad en la revista. La extensión máxima será de 4 páginas de 30 lineas y se admitirá una figura o una tabla y diez citas bibliográficas.

El número máximo de firmantes será de dos.

Imágenes médicas

Imágenes curiosas, insólitas o demostrativas. Se acompañarán con un texto breve, como máximo 1 página de 30 líneas, en el que se explique el caso clínico, con una breve discusión acerca de la importancia de la imagen. El número máximo de firmantes será de dos.

Resúmenes de Tesis doctorales

Elaborados por el autor, describirán el trabajo realizado; su extensión máxima será de 2 páginas de 30 líneas. Debe incluirse un apéndice con los datos correspondientes a Universidad, departamento, director de la tesis fecha de presentación.

Otros

a dirección de la revista considerará para su publicación cualquier artículo relacionado con la medicina en cualquier aspecto, aunque no se incluya exactamente dentro de los supuestos anteriores. En este caso se recomienda antes de su envío contactar con la dirección para acordar las características del mismo.

En el caso de que los trabajos enviados incluyan imágenes, figuras, tablas o textos sometidos a copyright, será responsabilidad de los autores la obtención de los permisos necesarios para su publicación.

Todas las opiniones o afirmaciones expresadas en los artículos corresponden a los autores de los mismos. Tanto e comité editorial como la SOGAMI declinan cualquier responsabilidad a este respecto.

Los trabajos publicados serán propiedad de GALCIA CLÍNICA, cediendo los autores todos los derechos a la misma 